\title{
格子ボルツマン法による水・油二相流れの数值シミュレーション Numerical Modeling of Multi-Phase (Water-Oil) Flow by Lattice Boltzmann Method
}

\author{
荒木 健 $^{1}$. 越村俊一 ${ }^{2}$ \\ Takeru ARAKI and Shunichi KOSHIMURA
}

\begin{abstract}
In the past years, the Lattice Boltzmann Method (LBM) has been developed and applied to simulate single phase flow with a free surface. In this paper, the free-surface tracking algorithms are newly implemented in a multi-phase LBM model to expand a capability of LBM to simulate a complex behavior of fluid flow. The model was verified by standard dam-break (single-phase) and oil--slick (two-phase) experiments and were found to be in good agreement with the results.
\end{abstract}

\section{1. はじめに}

格子ボルツマン法（Lattice Boltzmann Method, 以下 LBM）とは分子動力学に基づく数值流体解析手法（CFD） であり（McNamara・Zanetti, 1988; Qian ら, 1992; Chen・ Doolen, 1998)，流体を模擬した微視的仮想粒子の運動か ら巨視的な流体の流れを求める手法である。格子ボルッ マン方程式を支配方程式とし，粒子の各速度成分の頻度 (粒子分布関数 $f$ ) を変数として完全に陽的なスキームで 表現されるが，その解はNavier-Stokes式と一致する事が 数学的に保証されている (渡辺, 2006a, 2006b). 並列計 算に向いているため Multi-core CPUやGPUなどを用いた 計算の高速化が可能であり, Navier-Stokes 式の直接解法 より圧倒的に計算効率の高い手法として期待されてい る.また単相流のみならず様々な種類の流れを統一的に 取り扱うことが可能であり, 特に混相流に扔いては粒子 の運動から計算される流体密度の識別により界面形状が 自律的に求まるため, 界面の生成・消滅などの複雑流動 を容易に扱えるという特徵がある（二相系LBM）.

著者らは主に単相流について LBMに基づく新たな津 波数值解析手法の開発を行なってきた（大家ら，2008; 荒 木・越村, 2009）が，津波の陸上遡上に伴う油の流出・ 移流や，地滑り津波などといった防災上重要なマルチフ イジックス現象を取り扱うためには二相流のモデル化が 必要となる。しかし既往の二相流モデルに抒いて自由表 面の境界条件は確立されておらず，実現象への応用には 自由表面探索アルゴリズムの構築が課題であった。

そこで本研究では, 二相系LBMに扔ける自由表面探索 アルゴリズムを構築し，上記の複雑現象に対応する新た な数值解析手法の基礎となる計算手法を開発することを

1 正会員 修(工) 日本工営株式会社

2 正会員 博(工) 東北大学大学院准教授 工学研究科

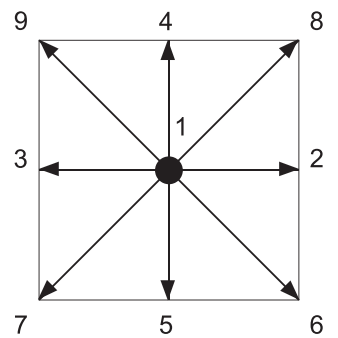

図-1ＬBMの2 次元 9 速度格子モデル

目的とする．まず「密度差の比較的小さい」二流体を対 象とした Grunauら（1993）の二相モデルに，単相流にお いて確立された Könerら（2005）の自由表面探索手法を 組み合わせ, 新たに自由表面を有する二相流れを解析す るモデルを提案する，そして鉛直二次元の流れ場におい て, ダムブレイク流れによる水・水の混合抒よび水・油 の混合を再現した水槽実験との比較を通してモデルの妥 当性を検討する.

\section{2. 格子ボルツマン法}

\section{（1）格子形状}

本研究では格子形状に図-192 次元 9 速度モデルを用い る. 粒子の運動はこの格子に沿った有限な方向に制限さ れ, 粒子の速度 $\mathbf{e}_{i}(i=1,2, \ldots .9)$ は,それぞれ $0(i=1), e(i=$ $2,3,4,5), \sqrt{2} e(i=6,7,8,9)$ となる. ここで, $e=\Delta x / \Delta t$ (格子間隔 $\Delta x$ 及び時間刻み幅 $\Delta t$ ) である.

\section{（2）格子ボルツマン方程式}

Grunauら（1993）の二相流モデルでは，互いに混ざり 合わない異なる流体の粒子を別個に扱う（赤青粒子モデ ル)。それぞれの色の粒子に対して, 時刻 $t$, 位置 $\mathrm{x} て ゙ \mathrm{i}$ 方 向の速度を持つ粒子の分布関数 $f_{i}^{k}(\mathrm{x}, t)$ の時間発展を, 並 進と衝突の二つの過程を表す格子ボルッマン方程式 (BGK方程式)により解く。ここで, 添字 $k$ は $k$ 成分 (r: redまたはb: blue）の粒子に関する式であることを表す。 


$$
f_{i}^{k}\left(\mathbf{x}+\mathbf{e}_{i} \Delta t, t+\Delta t\right)=\left(1-\frac{1}{\tau^{k}}\right) f_{i}^{k}(\mathbf{x}, t)+\frac{1}{\tau^{k}} f_{i}^{k(e q)} \cdots(1)
$$

ここで $\tau^{k}$ は単一時間緩和係数であり， $\tau^{k} に よ り$ 仮想的な 水粒子の局所的な運動が平衡状態に達する速さ（粘性） が決まる．流体の動粘性係数 $v$ と式（2）のような関係が 成り立っており，この值を変化させることにより動粘性 係数の異なる流体を取り扱う.

$$
\tau^{k}=\frac{1}{2}+3 \nu^{k} \frac{\Delta t}{\Delta x^{2}}
$$

\section{（3）局所平衡分布関数}

局所平衡分布関数 $f^{k(e q)}$ は局所平衡状態における粒子分 布関数であり, 各流体の密度 $\rho_{k}=\Sigma_{i} f_{i}^{k}$ および流速 $\mathbf{u}=\Sigma_{i, k}$ $\mathbf{e}_{i} f_{i}^{k} / \rho$ により求められる.

$$
\begin{gathered}
f_{i}^{k(e q)}=\left\{\begin{array}{l}
\rho_{k}\left(\frac{\lambda_{k}}{5+\lambda_{k}}-\frac{2}{3} \mathbf{u}^{2}\right) \\
\rho_{k}\left(\frac{1}{5+\lambda_{k}}-\frac{1}{6} \mathbf{u}^{2}+\frac{1}{3}\left(\mathbf{e}_{i} \cdot \mathbf{u}\right)+\frac{1}{2}\left(\mathbf{e}_{i} \cdot \mathbf{u}\right)^{2}\right) \\
\frac{\rho_{k}}{4}\left(\frac{\lambda_{k}}{5+\lambda_{k}}-\frac{1}{6} \mathbf{u}^{2}+\frac{1}{3}\left(\mathbf{e}_{i} \cdot \mathbf{u}\right)+\frac{1}{2}\left(\mathbf{e}_{i} \cdot \mathbf{u}\right)^{2}\right)
\end{array}\right. \\
\in\left\{\begin{array}{l}
i=1 \\
i=2, \cdots, 5 \\
i=6, \cdots, 9
\end{array}\right.
\end{gathered}
$$

ここで， $\lambda_{k}$ をパラメータとし二流体の密度比を変化させ ることができる，本モデルでは二流体の密度比を $\frac{\rho_{r}}{\rho_{b}}=$ $\frac{5+\lambda_{r}}{5+\lambda_{b}}$ とし, 局所平衡分布関数を上式のような形に決定 した。

\section{3. 自由表面探索アルゴリズム}

\section{（1）セルの分類}

二流体の界面形状については，粒子の運動から計算さ れる流体密度の識別により自律的に求めることができる が,自由表面については特別な操作が必要となる。VOF法 （Hirt・ Nichols, 1981）の類推から, 各セル内の流体の充 填率 $\varepsilon$ に応じて, その属性を空隙 $(\mathrm{G})$ 七ル $(\varepsilon=0)$, 界 面 (IF) セル $(0<\varepsilon<1)$, 流体 (F) セル $(\varepsilon=1)$ に分 類する. 界面セルは自由表面の位置を表し，そのセルの 位置により自由表面を探索できる。本研究ではさらに， 二流体の界面でありかつ気体との界面（自由表面）とな るセルを取り扱うため，各セルに含まれる粒子の色につ いても分類し, 空隙セルも含めて合計 7 種類に分類する. (図-2)。一成分の流体のみを含んでいる領域を赤 $(\mathrm{r})$ ま たは青（b）領域とし，二流体を含んでいる領域を紫 (p) 領域とする，そのセルでは異なる二流体の含有比に応じ てその中間の物性（ $\rho, \lambda, \tau)$ を持つセルとして扱う.

\section{（2）自由表面の境界条件}

界面セルは空隙セルと隣接するため, 境界条件式 （Könerら（2005））を用いて流入する粒子分布関数を補 完する必要がある。
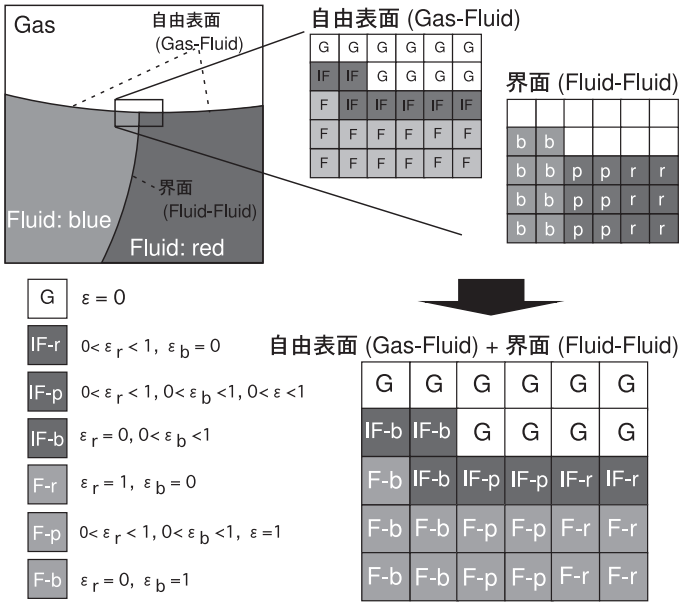

図-2 セル分類のジオメトリ（Köner et al. (2005)を拡張）

$$
f_{\tilde{i}}(\mathbf{x}, t+\Delta t)=f_{i}^{e q}\left(\rho_{A}, \mathbf{u}\right)+f_{\tilde{i}}^{e q}\left(\rho_{A}, \mathbf{u}\right)-f_{i}(\mathbf{x}, t)
$$

ここで, 添字 $\tilde{i}$ は $i$ と逆方向であることを意味し, $\mathbf{e}_{\tilde{i}}=-\mathbf{e}_{i}$ である，界面に打いて液体（流体七ル）と空気（間隙セ ル）の流速は等しくそれぞれが及ぼす力も等しいと考え， uは界面セルでの流体の速度，また空気の密度 $\rho_{A} に は$ 流 体の基準密度を用いる．界面での力の釣り合いを保つた め, 次式で求められる界面の傾き $\mathbf{n}$ 考慮し, $\mathbf{n} \cdot \mathbf{e}_{\tilde{i}}>0$ が成り立つ場合，粒子分布関数を補完する。

$$
\mathbf{n}=\frac{1}{2}\left(\begin{array}{c}
\epsilon\left(\mathbf{x}_{l-1, m}\right)-\epsilon\left(\mathbf{x}_{l+1, m}\right) \\
\epsilon\left(\mathbf{x}_{l, m-1}\right)-\epsilon\left(\mathbf{x}_{l, m+1}\right)
\end{array}\right)
$$

ここで, $\mathrm{x}_{l, m}$ はセルの座標を表している，なお，㱖領域 では赤拉よび青粒子を含んでいるため，式（4）で求め た值に含有比を乗じ，各粒子へ分配する.

$$
f_{\tilde{i}}^{k}(\mathbf{x}, t+\Delta t)=f_{\tilde{i}}(\mathbf{x}, t+\Delta t) \times \frac{\rho_{k}}{\rho}
$$

\section{（3）質量の計算}

充填率 $\varepsilon$ は, 各セル内の質量 $m$ と密度 $\rho$ の比で表す. 界面セルにおける質量の変化量は，次式のように隣り合 うセル同士の粒子分布関数のやりとりから求める.

$$
\begin{gathered}
\Delta m_{i}(\mathbf{x}, t)=\left\{\begin{array} { c } 
{ 0 } \\
{ f _ { \tilde { i } } ( \mathbf { x } + \mathbf { e } _ { i } , t ) - f _ { i } ( \mathbf { x } , t ) } \\
{ ( f _ { \tilde { i } } ( \mathbf { x } + \mathbf { e } _ { i } , t ) - f _ { i } ( \mathbf { x } , t ) ) \frac { \epsilon ( \mathbf { x } + \mathbf { e } _ { i } , t ) + \epsilon ( \mathbf { x } , t ) } { 2 } }
\end{array} \cdot \left(\begin{array}{l}
G \\
F \\
\mathbf{x}+\mathbf{e}_{i} \in
\end{array}\right.\right.
\end{gathered}
$$

周囲の各セルとの質量の変化量を全方向に渡って足し合 わせることで，次ステップでの質量が求まる.

$$
m(\mathbf{x}, t+\Delta t)=m(\mathbf{x}, t)+\sum_{i=1}^{9} \Delta m_{i}(\mathbf{x}, t)
$$




\section{（4）界面セルの判定と変換}

各セルの質量および密度の值から求めた流体の充填率 とにより，界面セルが「流体で満たされた $(1<\varepsilon) 」 か$ 「空になった $(\varepsilon<0) 」$ かを判断し，七ルの状態を変換す る.ここで, 界面セルが流体で満たされた $(1<\varepsilon)$,また は空になった $(\varepsilon<0)$ ということは, 界面が隣接するセ ルへ移動したということを意味する，そのため，界面セ ルの変換に伴い, 周囲の隣接する流体セルまたは空隙セ ルが新たに界面セルに変換される（図-3），その際に元の 界面セルに打いて生じる余分な質量（多く流入しすぎた 分 $(1<\varepsilon)$ または, 流出しすぎた分 $(\varepsilon<0))$ は質量保 存するように周囲の隣接セルへ分配する。このようにし て1ステップ毎に界面セルを追跡することで自由表面の 位置を決定する。

\section{4. 二相流れの数値解析}

\section{（1）水・油の混合}

縦 $20 \mathrm{~cm} \times$ 横 $20 \mathrm{~cm} \times$ 奥行 $10 \mathrm{~cm}$ の塩化ビニル製実験水槽 を作成し，ゲート急開により発生する二相流れ場の再現 実験を行った．水槽をゲートにより二分し，左側に着色 した水を，右側にキャノーラ油を高さ $4 \mathrm{~cm}$ まで貯め，手 動でゲートを急開した．LBMによる再現計算には表-2の パラメータを用い，壁面境界条件はS Slip 条件とした。 赤および青流体（キャノーラ油および水）の物性值は, $\rho_{b} / \rho_{r}=1 / 0.9 \quad\left(\lambda_{b}=4.0\right.$ および $\left.\lambda_{r}=3.1\right), v_{b} / v_{r}=1 / 30 \quad\left(\tau_{b}=\right.$ 0.509 および $\left.\tau_{r}=0.77\right)$ とした.

図-4および図-5に実験結果と数值計算結果の比較を示 す. 図-4は高速ビデオカメラで撮影した実験画像と数值 計算結果の比較であり，図-5 は水槽内の各地点における 水および油の各層の厚さの時間変化である. 実験值は画 像から目視にて界面を抽出し求めた。な掞，数值計算結 果は油を薄い灰色, 着色した水を濃い灰色で示している. ゲート急開後，水が油層の下へ潜り反対に油が水の上を 広がる様子を再現されており, 界面形状についても概ね 一致していることが確認できる．水・油の界面や水・ 油・空気の界面についても安定して計算できており，本 モデルの自由表面探索アルゴリズムが妥当であるといえ る。ただし, 実験同様油先端の方が水先端よりも早く側 壁面に達するが，数值計算では実験に比べ油先端の移動 速度が遅くなっている. 図-5からも，A点においては誤 差が比較的大きくなっていることがわかる．特に A 点の $\mathrm{t}=0.8 \mathrm{~s}$ から $1.2 \mathrm{~s}$ 付近で誤差が大きいが，これは界面の移 動速度が遅いためであると考えられる，その点を除くと

表-1 水・油の混合：計算パラメータ

\begin{tabular}{c|c|c|c}
\hline grid resolution & $\Delta x(\mathrm{~m})$ & $\Delta t(\mathrm{~s})$ & $\tau_{b}, \tau_{r}$ \\
\hline $50 \times 200$ & 0.001 & $2 \times 10^{-4}$ & $0.509,0.770$ \\
\hline
\end{tabular}

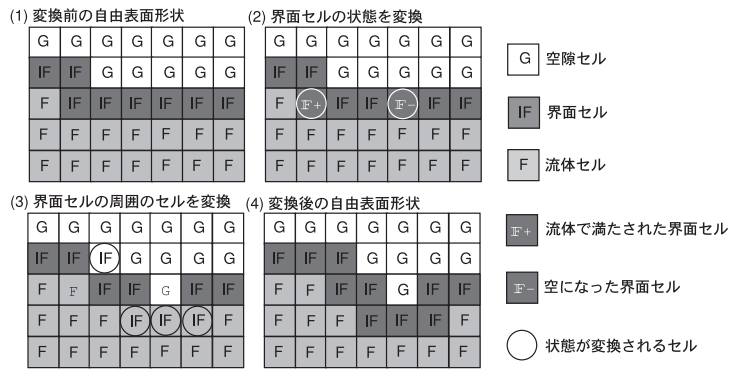

図-3 セル状態の変換（Thürey (2003)を参考に作成）

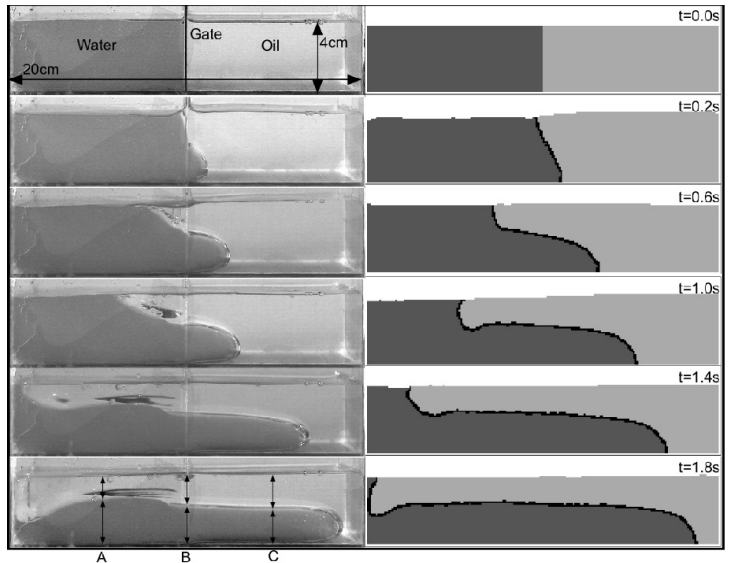

図-4 水・油の混合の界面形の時間変化 (左：実験画像，右：LBM）
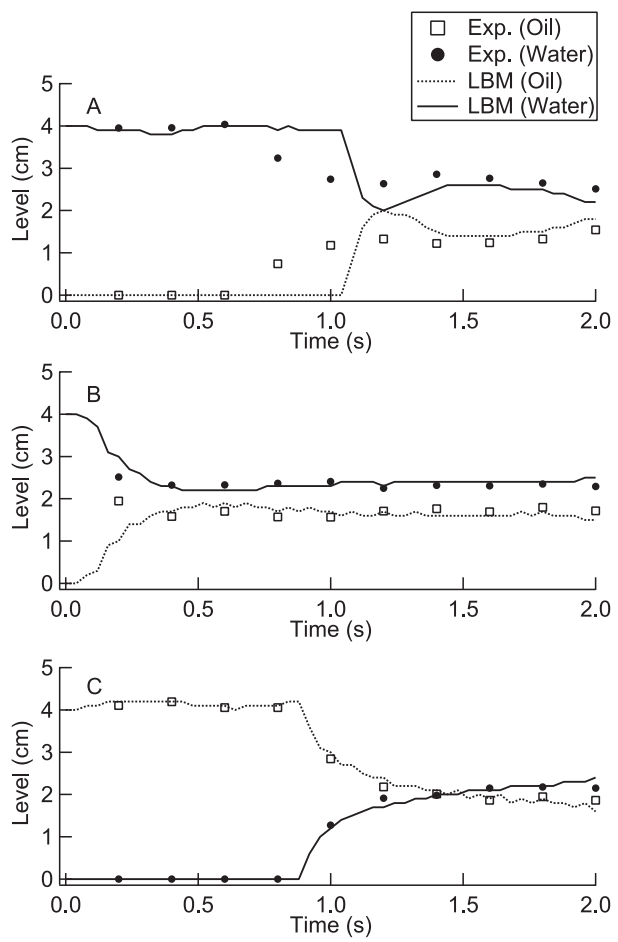

図-5 水および油の層厚の時間変化

(A：左壁面から $5 \mathrm{~cm}, \mathrm{~B}$ ：中央, C : 右壁面から $5 \mathrm{~cm}$ ) 
A 点の油の先端通過後や B 点および C 点においては実験 值と良く一致していることが確認できる.

\section{（2）Violent flowにおける水・水の混合}

次に，津波先端部のような激しい流れ場においてモデ ルの適用性を検証するため，ダムブレイク流れの再現計 算を行なう。Janosi ら（2004）の実験に倣い，計算領域 を図-6のように設定し，水路の上流側には透明な水を， 下流側には着色した水を溜め，ゲートを急開した。上流 側の初期水深 $d_{0}$ は $15 \mathrm{~cm}$ とし, 下流側水深 $d$ は $5 \mathrm{~mm}$ から $70 \mathrm{~mm}$ まで変化させた。再現計算では上流および下流の 水をそれぞれ同じ物性を持つ別の流体として扱い，計算 パラメータは表-2の值を用いた。なおゲート急開の速度 は $1.0 \mathrm{~m} / \mathrm{s}$ と仮定した。

図-7および図-8に実験結果と数值計算結果の比較を示 す. 図-7は下流側水深 $d$ を変化させた各ケースの比較で ある。透明な水は水圧が高い底面付近から流れ込み，着 色水を押しのけ潜り込むように進む。数值計算結果は, 実験と同様に透明な水が着色水を押しのけている。また 下流側水深が高くなる程，水を押し出す量が少なくなり 同時刻での界面の移動距離は短くなるなど，実験と同様 の挙動を示していることがわかる．細かな界面形状や砕 波形状の再現性には課題が残るが，界面挙動を良く再現 できていることが確認できる．図-8は $d=15 \mathrm{~mm}$ の場合の 界面形の時間変化の比較である。実験と同様に，前方だ けでなく後方（上流側）へも砕波が起こりマッシュルー 厶型の界面形を呈する．前方への砕波は数值計算では先 端が先鋭化する前に崩れており，細かな砕波形状までは 一致していないが，砕波位置については概ね一致してい る.また，後方への砕波により激しい混合が生じているた め正確な界面の抽出は難しいが，界面について概ね移動 距離が一致していると判断できる。ただし図-8に見られ る段波後方での混合拡散現象については，本モデルの適 用範囲外であり完全な再現は難しい。以上から，細かな 界面形状や砕波形状の再現性には課題が残るものの，本 手法が激しい流れ場においても実用上十分適用可能であ ることがわかる。

表 2 水・水の混合：計算パラメータ

\begin{tabular}{c|c|c|c}
\hline grid resolution & $\Delta x(\mathrm{~m})$ & $\Delta t(\mathrm{~s})$ & $\tau_{b}, \tau_{r}$ \\
\hline $200 \times 1040$ & 0.001 & $5 \times 10^{-5}$ & 0.518 \\
\hline
\end{tabular}

（3）津波侵入による油の移流を想定したテストケース

さらに本モデルの適用事例として，津波の陸上遡上に 伴い広がる油を想定した数值計算を行ない，油の密度の 違いによる挙動変化について検討する。臨海地域に貯蔵 される種々の石油製品を想定し，油の比重は 0.6 から 0.9 まで変化させた。

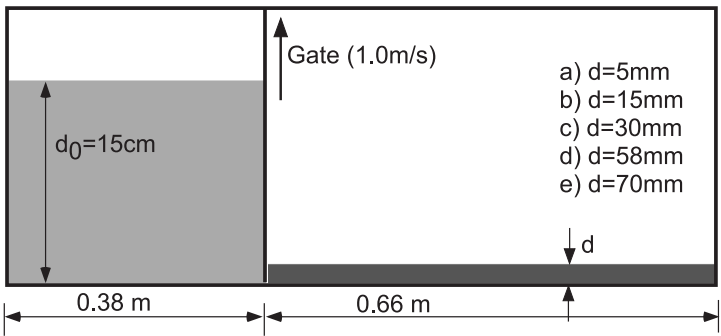

図-6＼cjkstart再現計算の諸元（Janosi ら, 2004）

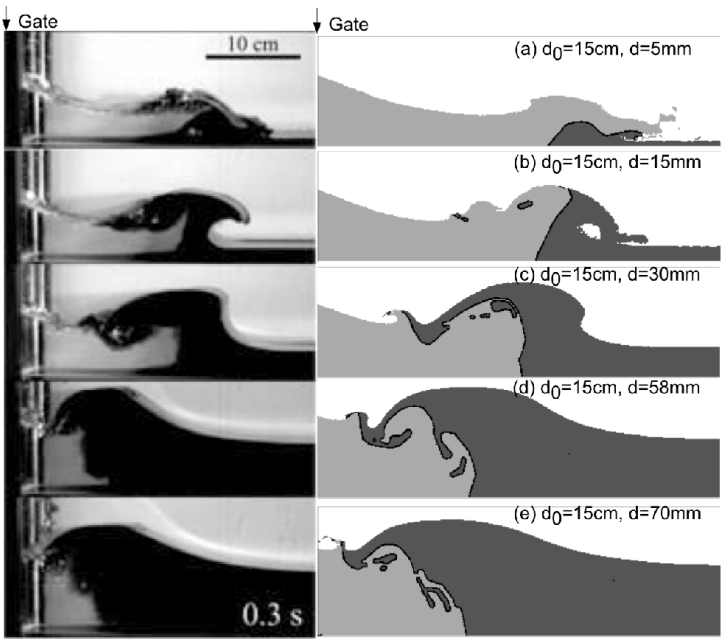

図-7 $\mathrm{t}=0.3 \mathrm{~s}$ でのスナップショット

（左：Janosiら（2004）の実験，右：LBM）

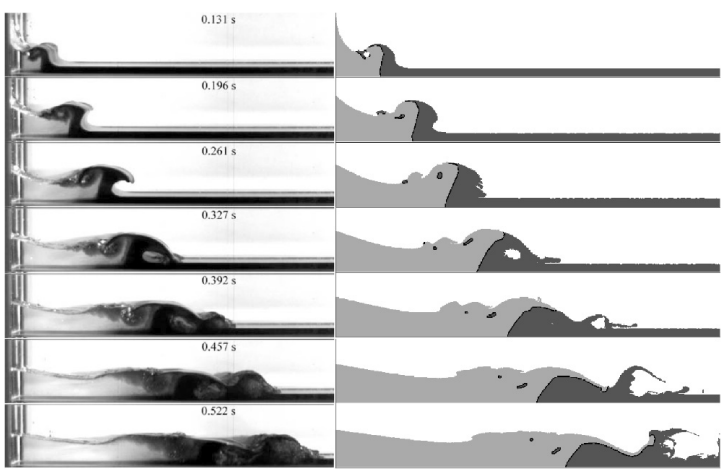

図-8 水の混合の界面形の時間変化 (左：Janosiら (2004）の実験, 右：LBM). 上流側水深 $d_{0}=15 \mathrm{~cm}$, 下流側水深 $d=15 \mathrm{~mm}$.

図-9には二流体の密度比が（a）1:0.9および（b） 1:0.6 の2ケースの比較を示す．ケース（b）では密度が大きい ケース（a）に比べ油塊の移動速度が大きくなり，油塊 が長い距離を移動する。本計算ケースでは水が油を巻き 込んで進むような挙動は見られなかったが，数值計算が 鉛直二次元の流れ場であることや，粗い解像度であるこ とが原因であると考えられる，津波侵入による油の移流 現象への適用へ向けて，今後は水理実験などから得られ 


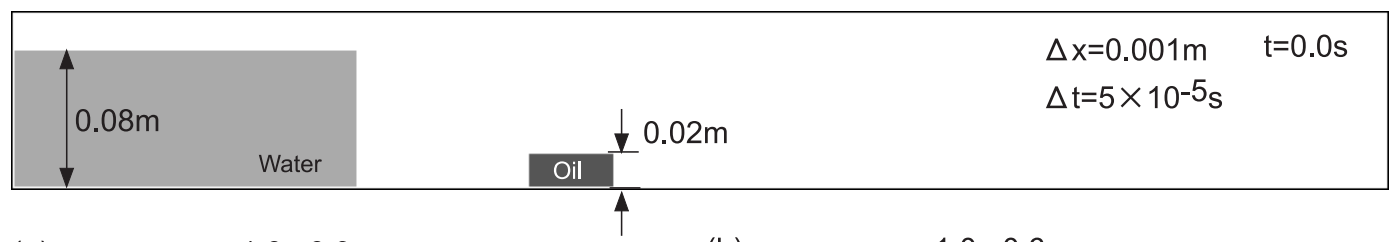

(a) $\rho_{\text {water }}: \rho_{\text {oil }}=1.0: 0.9$

(b) $\rho_{\text {water }}: \rho_{\text {oil }}=1.0: 0.6$

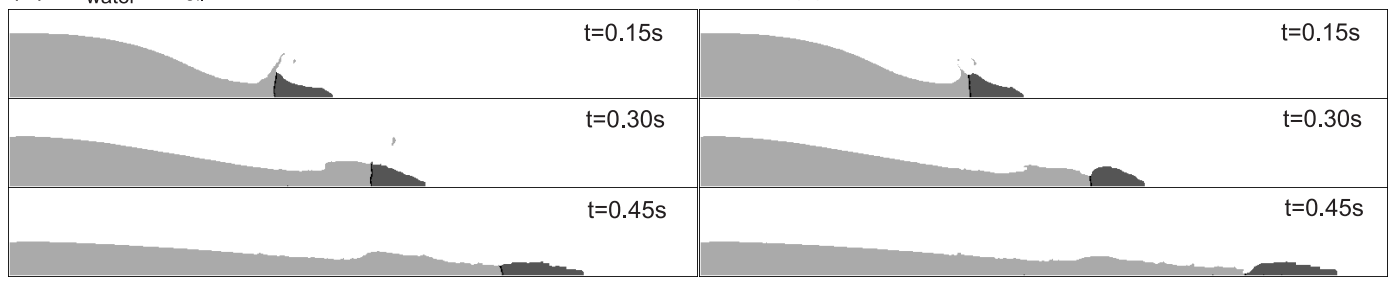

図-9＼cjkstart津波侵入による油の移流を想定したテストケース（（a）密度比 $1 ： 0.9,(b)$ 密度比 $1 ： 0.6)$

る結果との比較検証が必要である.

\section{5. 結論}

本研究で得られた結論を以下に列挙する.

二相流を対象とした LBMの自由表面探索アルゴリズ 厶を構築し, 水㧍よび油の混合現象の実験結果を用いて 検証した. 水・油・空気の界面を安定して計算すること ができ, 自由表面および水・油の界面形状を良好に再現 することができた。また水槽内の各地点に扔ける水・油 の層厚の時間変化についても実験結果とほぼ一致し, 本 モデルによって自由表面を有する密度の異なる二相流れ を精度よく計算可能であることが示された。

砕波を含む激しい流れ場に打ける二相系 LBMの再現 性について, 着色した水によるダムブレイク流れの実験 と比較して検証した．水の激しい混合による複雑な界面 形状や砕波の再現性には課題が残るものの, 砕波位置や 二流体の界面位置などは概ね一致しており，本モデルが 複雑な流れ場に対しても有効であることが示された.

さらに, 本モデルの適用事例として津波による油の流 出や移流現象について, 種々の石油製品を想定した油の 巻き込み・移流現象を再現した. 今後は水理実験などか ら得られる結果との比較検証が必要である.

また, 本研究で開発した自由表面を含む二相系 LBM では, 二流体の密度比が 1:0.6程度まで計算できることを 確認した。本モデルを基礎とし, 物性の異なる様々な二 流体の衝突現象を再現するモデルへと拡張していくこと が今後の課題である.

謝辞 : 本研究の一部は科学研究費補助金 (挑戦的萌芽, 代表：越村俊一, 課題番号：21651078), および独立行

政法人原子力安全基盤機構（JNES）の補助を受けて実施 された。ここに記して謝意を表する.

参 考 文 献

荒木 健・越村俊一（2009）：格子ボルッマン法による自由表 面流れの解析, 海岸工学論文集, 第 56 巻, pp. 56-60.

大家隆行・越村俊一・荒木 健 (2008)：格子ボルツマン法に 基づく津波遡上シミュレーション手法の開発，海岸工学 論文集, 第 55 卷, pp. 221-225.

渡辺 正 (2006a)：格子ボルッマン法（1）, ボルッマン方程 式から格子ボルッマン方程式へ, 応用数理, Vol. 16, No. 1, pp. 31-35.

渡辺 正 (2006b)：格子ボルッマン法 (2)，ボルッマン方程 式からナビエーストークス方程式へ, 応用数理, Vol. 16, No. 2, pp. 64-69.

Chen, S. and G. D.Doolen (1998) : Lattice Boltzmann Method for fluid flows, Annual Review of Fluid Mechanics, 1998 Vol.30, pp. 329-364.

Grunau, D., S., Chen and K., Eggert (1993) : A Lattice Boltzmann Model for Multi-phase Fluid Flows, Physics Fluids A 5 (10), 2557.

Hirt, C. W. and B. D. Nichols (1981) : Volume of Fluid (VOF) Method for the Dynamics of Free Boundaries, Journal of Computational Physics, Vol. 39, pp. 201-225.

Janosi, I. M., D. Jan, K. G. Szabo and T. Tel (2004) : Tur-bulent drag reduction in dam-break flows, Experiments in Fluids, Vol. 37, pp. 219-229.

Körner, C., M. Thies, T. Hofmann, N. Thürey and U. Rüde (2005) : Lattice Boltzmann Model for Free Surface Flow for Modeling Foaming, Journal of Statistical Physics, Vol. 121, (1-2), pp.179196.

McNamara, G. R. and G. Zanetti (1988) : Use of the Boltz-mann Equation to Simulate Lattice-Gas Automata, Physical Review Letters, 61, pp. 2332.2335.

Qian, Y. H., D. d' Humieres and P. Lallemand (1992) : Lattice BGK Models for Navier-Stokes Equation, Europhysics Letters, 17 (6), pp. 479.484.

Thürey, N. (2003) : A single-phase free-surface lattice boltz-mann method, University of Erlangen-Nuremberg, Master thesis, 60p. 